\title{
Person-in-the-barrel syndrome following cervical spine surgery: illustrative case
}

\author{
Lisa B. E. Shields, MD, ${ }^{1}$ Vasudeva G. Iyer, MD, ${ }^{2}$ Yi Ping Zhang, MD, ${ }^{1}$ and Christopher B. Shields, MD ${ }^{1,3}$ \\ ${ }^{1}$ Norton Neuroscience Institute, Norton Healthcare, Louisville, Kentucky; ${ }^{2}$ Neurodiagnostic Center of Louisville, Louisville, Kentucky; and ${ }^{3}$ Department of Neurological \\ Surgery, University of Louisville School of Medicine, Louisville, Kentucky
}

BACKGROUND Person-in-the-barrel syndrome is characterized by bilateral brachial diplegia, intact cranial nerves, and preserved lower-extremity strength. Most cases are due to bilateral supratentorial brain lesions at the border zone of the anterior and middle cerebral artery vascular territories. This condition has been observed with spinal pathology, primarily involving vascular dissection and thromboembolism.

OBSERVATIONS The authors' case is the first in the literature to highlight person-in-the-barrel syndrome immediately following cervical spine surgery. Weakness of the deltoids, biceps, infraspinatus, and brachioradialis was observed bilaterally postoperatively. Electromyograph (EMG)-nerve conduction velocity (NCV) studies revealed a cervical radiculopathy involving C5 and C6 bilaterally with denervation of the deltoids, biceps, and brachioradialis. Within 8 months of cervical spine surgery, the patient regained improvement of the bilateral brachial diplegia.

LESSONS EMG/NCV studies play a valuable role in detecting cervical radiculopathy after cervical spine surgery in patients with bilateral brachial diplegia. The authors postulate that this condition may have occurred following neck hyperextension during cervical cage placement, increasing the foraminal stenosis at C4-5 and C5-6 and worsening the C5 and C6 radiculopathy. Spinal surgeons should be cognizant of person-in-the-barrel syndrome that may ensue following cervical spine surgery and promptly identify and treat this condition to offer the best prognosis for a favorable patient outcome.

https://thejns.org/doi/abs/10.3171/CASE20165

KEYWORDS man-in-the-barrel syndrome; person-in-the-barrel syndrome; brachial diplegia; cervical; electromyography; nerve conduction study

Following Dide and Lhermitte's initial description of brachial diplegia in $1917,{ }^{1}$ Mohr used the term "distal field infarction" in 1969 to describe infarcts in the middle and anterior cerebral arterial border zone caused by systemic hypoperfusion leading to bilateral brachial paresis. ${ }^{2}$ Sage and Van Uitert coined the term "man-in-the-barrel" in 1986 in their study of comatose patients who experienced systemic hypoperfusion with resulting bilateral upper-extremity paresis. ${ }^{3}$ Their term visualized a patient with these symptoms as constrained within a barrel. Similar to the term "stiff-person syndrome," we are recoining "man-in-the-barrel syndrome" as "person-in-the-barrel syndrome" to reflect up-to-date societal terminology.

Most cases of person-in-the-barrel syndrome are caused by bilateral supratentorial brain lesions due to ischemia in the border zone between the anterior and middle cerebral arteries and by bilateral cerebral hypoperfusion. ${ }^{4-8}$ Other cranial sources of this condition include pontine lesions due to ischemic infarction, hemorrhagic contusion, central pontine myelinolysis, lesions attributed to multiple sclerosis, and multiple bilateral cerebral metastasis.,5,7-10 Bilateral lesions of the brachial plexus have also been associated with personin-the-barrel syndrome. ${ }^{5,7,11,12}$ Person-in-the-barrel syndrome has rarely been described as being caused by spinal pathology and primarily involves vascular dissection and thromboembolism. ${ }^{13}$ The prognosis is better for noncomatose patients with an extracranial source of person-in-the-barrel syndrome who experience ischemia for a short duration. ${ }^{3,5,8,9}$ Although unilateral C5 palsy is well known following cervical spine surgery of C4-5, bilateral C5-6 palsy leading to person-in-the-barrel syndrome has not been reported after cervical spine surgery.

Because of the wide variation in motor and sensory deficits, as well as radiological findings in patients with person-in-the-barrel syndrome caused by spinal pathology in the literature, there was a need to accurately define this condition. We defined person-in-the-barrel syndrome following cervical spine surgery as occurring in patients who had postoperative evidence of C5-6 abnormalities bilaterally as ascertained by radiological studies, comprehensive and detailed physical examination of the upper extremities, and electromyography

ABBREVIATIONS ACDF = anterior cervical discectomy and fusion; CT = computed tomography; EMG = electromyography; NCV = nerve conduction velocity; OT = occupational therapy; $\mathrm{PT}=$ physical therapy.

INCLUDE WHEN CITING Published February 22, 2021; DOI: 10.3171/CASE20165.

SUBMITTED December 20, 2020. ACCEPTED December 30, 2020.

(C) 2021 The authors, CC BY-NC-ND 4.0 (http://creativecommons.org/licenses/by-nc-nd/4.0/), 
(EMG) studies. We present a unique case as fulfilling these criteria. The importance of the physical examination of the upper extremities and EMG studies in elucidating this extraordinarily rare condition following cervical spine surgery is described. We also discuss the mechanism involved in producing this disorder in this setting, as well as patient management and long-term outcomes.

\section{Illustrative Case}

\section{History, Physical Examination, and Radiological Imaging}

A 62-year-old man (height 6 feet 6 inches [1.98 m], weight $220 \mathrm{lb}$ [ $99.8 \mathrm{~kg}$ ], body mass index $25.24 \mathrm{~kg} / \mathrm{m}^{2}$ ) had the onset of weakness of the upper-extremity muscles bilaterally with an inability to elevate the arms at the shoulder and flex the elbows. His symptoms began immediately following an anterior cervical vertebrectomy at C4 and C5 and a fusion with a cage and plate from $\mathrm{C} 3$ to $\mathrm{C} 6$, as well as an anterior cervical discectomy and fusion (ACDF) and plate at C6-7. Hypotension was not documented either intra- or postoperatively. A head and neck computed tomography (CT) scan 2 days postoperatively demonstrated prevertebral soft-tissue swelling at the site of the fusion. Five days later, he underwent a posterior cervical decompression and foraminotomies at C4-5 bilaterally with a fusion from C3 to C7. EMG performed 1 month before his anterior cervical surgery demonstrated bilateral carpal tunnel syndrome, left cubital tunnel syndrome, and chronic cervical radiculopathy of $\mathrm{C} 6$ and $\mathrm{C} 7$ on the left and $\mathrm{C} 7$ on the right. On examination, there was moderate weakness of the deltoids, biceps, infraspinatus, and brachioradialis bilaterally.

\section{EMG-Nerve Conduction Velocity Studies of the Hands}

Postoperative needle EMG demonstrated denervation of the deltoids, infraspinatus, and biceps bilaterally. The patient recruited 1-2 motor units in the left biceps but none in the right biceps or deltoids. The right brachioradialis showed no motor units, whereas he recruited 2-3 motor units on the left. The triceps revealed decreased motor unit recruitment with increased polyphasics. EMG confirmed marked acute denervation changes in the $\mathrm{C} 5$ and $\mathrm{C} 6$ distributions bilaterally, as well as chronic denervation/reinnervation changes in the $\mathrm{C} 7$ distribution bilaterally. The primary difference between the pre- and postoperative EMG studies was the de novo presence of denervation in the C5 and C6 distributions bilaterally in the latter study.

\section{Neurosurgical Follow-Up}

The patient underwent physical therapy (PT) and occupational therapy (OT) following his second operation. He continued to experience profound weakness of right shoulder abduction and right elbow flexion 4 months after his cervical spine surgery. The weakness almost completely resolved within 8 months following surgery.

\section{Discussion}

Although the majority of cases of person-in-the-barrel syndrome involve supratentorial lesions triggered by systemic hypotension, this condition is also associated with myriad spinal pathologies (Table 1). ${ }^{4-10,13-26}$ Cervical spinal cord ischemia/infarction is the most commonly reported cause of spinal person-in-the-barrel syndrome.,4,6,15 Mechanisms responsible for this occurrence include thrombosis of the vertebral artery causing anterior spinal artery hypoperfusion, dissection of the vertebral artery, stenosis of the subclavian artery, and a medullary infarct due to anterior spinal artery occlusion. ${ }^{4-7,15}$ The differential diagnosis of isolated brachial diplegia of the proximal muscles consists of person-in-the-barrel syndrome, Bell's cruciate paralysis, and anterior vascular spinal cord syndrome. Described by Bell in 1970,
TABLE 1. Person-in-the-barrel syndrome resulting from spinal pathology in the literature

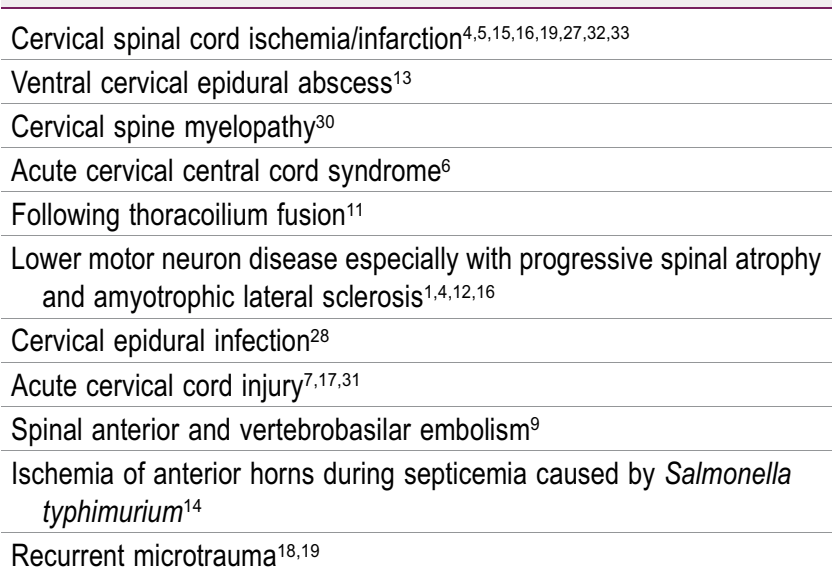

cruciate paralysis results from injury of the upper portion of the pyramidal decussation, which may be caused by an odontoid fracture, cervical hyperextension injury, or acute hydrocephalus following suboccipital craniectomy. ${ }^{9,27}$ Acute vascular spinal cord syndrome results from ischemia of the anterior spinal artery and is marked by symmetric weakness affecting the upper extremities more than the spastic lower extremities and by bowel and bladder dysfunction. ${ }^{16}$ All three conditions may be due to infratentorial disease; however, person-in-the-barrel syndrome may also be a sequela of supratentorial disease.

Anecdotal reports of person-in-the barrel syndrome that developed after surgery include two following abdominal procedures, ${ }^{11,12}$ two after cardiac surgery, ${ }^{28,29}$ and one after a thoracic spinal procedure (Table 2). ${ }^{9}$ All five of these patients attained good return of upperextremity function within several months of their surgical procedure. Joaquim and colleagues reported the only case of person-in-the-barrel syndrome caused by hyperextension following spinal surgery, specifically, an extensive revision involving thoracoilium instrumentation and fusion for iatrogenic and degenerative scoliosis, progressive kyphosis, and sagittal imbalance. ${ }^{9}$ The patient had previously undergone T11-S1 fusion for lumbar spinal stenosis and scoliosis. The duration of the operation was 510 minutes with an estimated blood loss of $2500 \mathrm{~mL}$ for which she intraoperatively received 8 units of packed red blood cells, 3 units of fresh-frozen plasma, and $1500 \mathrm{~mL}$ of cell-saved blood. The patient experienced a 2-hour period of mild hypotension (mean arterial pressure $50-60 \mathrm{~mm} \mathrm{Hg}$ ) intraoperatively followed by severe hypotension (mean arterial pressure $35-50 \mathrm{~mm} \mathrm{Hg}$ ) for 30 minutes 6 hours postoperatively. As a result of negative findings on imaging studies of the head and cervical spine after surgery, the authors attributed the patient's person-in-the barrel symptoms to intraand postoperative hypotension.

Unilateral postoperative C5 palsy is a well-recognized complication following decompressive cervical surgery, particularly at the C4-5 level, which may occur after posterior cervical decompression surgery such as laminoplasty or anterior cervical spinal surgery. ${ }^{30}$ In Hashimoto and colleagues' study of 199 patients who underwent ACDF, 17 (8.5\%) patients experienced postoperative $\mathrm{C} 5$ palsy. ${ }^{30}$ These authors defined a C5 palsy as when patients demonstrated a deterioration in muscle power of the deltoid and biceps brachii by at least one grade in muscle testing without aggravation of lower-extremity function. The C5 palsy developed after ACDF of three or more levels in the majority of patients, 
TABLE 2. Person-in-the-barrel cases following surgery in the literature

\begin{tabular}{|c|c|c|}
\hline Study & Procedure & Pathology \\
\hline $\begin{array}{l}\text { Hurley and Wood, } \\
1993^{28}\end{array}$ & CABG in hypertensive patient & $\begin{array}{l}\text { MRI: ischemia with hypoperfusion leading to border zone infarction between the anterior and } \\
\text { middle cerebral arteries; rapidity of fall in blood pressure responsible for brain damage }\end{array}$ \\
\hline $\begin{array}{l}\text { Joaquim et al., } \\
2008^{9}\end{array}$ & $\begin{array}{l}\text { Thoracoilium instrumentation } \\
\text { and fusion }\end{array}$ & No radiological evidence of lesion; intra- and postoperative hypotension \\
\hline $\begin{array}{l}\text { Present study, } \\
2020\end{array}$ & Cervical spine surgery & $\begin{array}{l}\text { Weakness of deltoids, biceps, infraspinatus, and brachioradialis bilat postoperatively; EMG-NCV } \\
\text { studies: cervical radiculopathy involving C5 and C6 bilat }\end{array}$ \\
\hline
\end{tabular}

CABG = coronary artery bypass graft; SSEP = somatosensory evoked potential.

and most patients with severe C5 palsy after ACDF had preexisting asymptomatic damage of the anterior horn cells at C3-4 and C4-5. Several etiologies have been proposed as causing postoperative unilateral C5 palsy, including direct injury to the nerve root, tethering of nerve roots because of a shift of the spinal cord associated with anchoring of the nerve root, and a spinal cord vascular injury such as local reperfusion injury or decompression of a chronic compressive cervical cord disorder. ${ }^{30-34}$

\section{Observations}

The present case is the first to describe person-in-the-barrel (C5-6) syndrome following cervical spine surgery. The patient experienced isolated bilateral diplegia immediately after the cervical spine procedure. Weakness of the deltoids, biceps, infraspinatus, and brachioradialis was observed, and EMG-nerve conduction velocity (NCV) studies revealed a bilateral cervical radiculopathy involving $\mathrm{C} 5$ and $\mathrm{C} 6$. Within 8 months of cervical spine surgery, the patient regained near-complete recovery of the bilateral brachial diplegia following a course of PT and OT.

We speculate that a unique surgical mechanism may have led to the patient's person-in-the-barrel syndrome in this case (Fig. 1). The patient initially underwent an anterior vertebrectomy and cage placement. With the anterior approach, adequate foraminotomies are challenging. As this patient had severe foraminal stenosis extending from C3 to C7 preoperatively, the foramen was further narrowed from cervical hyperextension when the cage was placed. This mechanism creates a fulcrum effect in which there is a wide exposure anteriorly with distraction from $\mathrm{C} 3$ to $\mathrm{C} 6$ to allow for cage insertion. The foramina posteriorly become severely narrowed, thereby compressing the $\mathrm{C} 5$ and $\mathrm{C} 6$ nerve roots bilaterally. Five days later he underwent a posterior cervical decompression at C4-5 bilaterally with posterior cervical fusion from $\mathrm{C} 3$ to $\mathrm{C} 7$.

Based on our case, we recommend that if a patient presents with severe foraminal stenosis, we suggest performing the foraminotomies
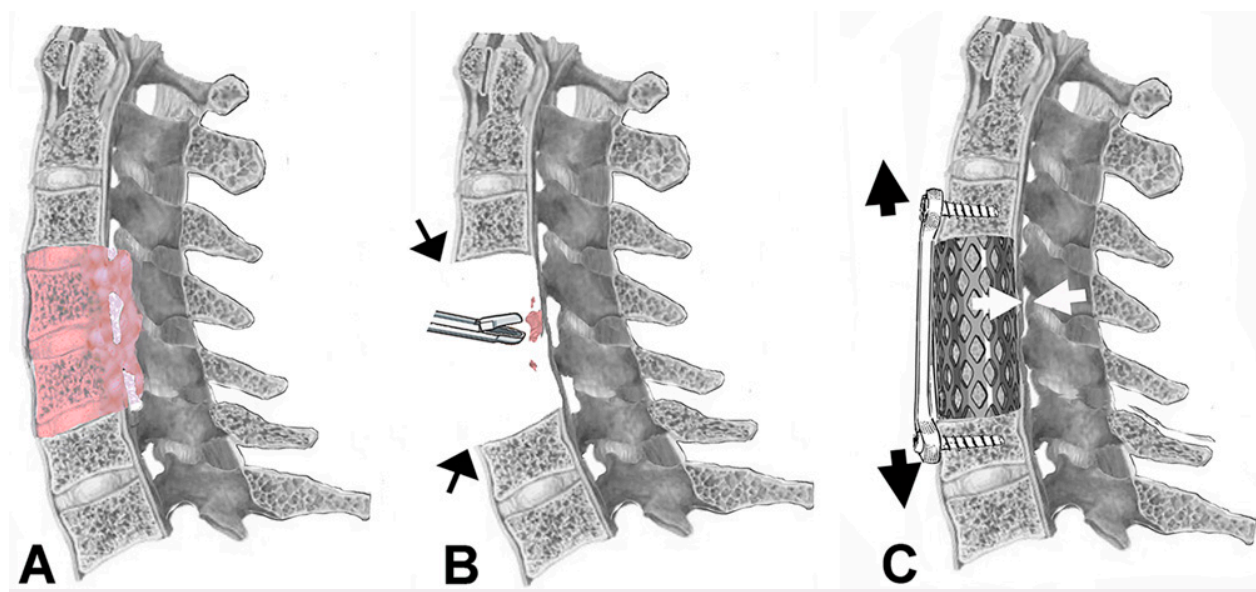

FIG. 1. A: Preoperative central spinal canal and foraminal stenosis (pink). B: Intraoperatively following C4 and $\mathrm{C} 5$ corpectomy. Arrows indicate the direction of compressive forces following the $\mathrm{C} 4$ and $\mathrm{C} 5$ vertebrectomy. C: Cervical cage placement caused cervical spine hyperextension producing increased foraminal stenosis, particularly because there had been incomplete lateral foraminal decompression and $\mathrm{C} 5$ radiculopathy. Black arrows indicate the distractive forces applied to C3 and C6 vertebral bodies following placement of the cage. White arrows demonstrate severe foraminal compression at C4-5. 
at C4-5 and C5-6 as the first stage, followed by an anterior approach to decompress the cord. Alternatively, our case may have been caused by ischemia of the central spinal cord (as seen in other person-in-thebarrel cases with cervical pathology) or bilateral nerve root injury (as observed in unilateral C5 palsy). The patient's position on the operating table during surgery that may cause stretching of both $\mathrm{C} 5$ and $\mathrm{C} 6$ nerve roots should also be considered.

\section{Lessons}

Spinal surgeons should be aware that person-in-the-barrel syndrome may occur immediately following anterior cervical spine surgery. A detailed physical examination of the upper extremities and EMGNCV studies play important roles in confirming cervical radiculopathy after cervical spine surgery in patients with bilateral brachial diplegia. Prompt identification of person-in-the-barrel syndrome after cervical spine surgery and treating affected patients with rehabilitation offer the best prognosis for complete recovery.

\section{Acknowledgments}

We acknowledge Norton Healthcare for their continued support

\section{References}

1. Dide M, Lhermitte J. Spasmodic brachial diplegia following gunshot wounds in the cervical region. Article in French. Prog Med (Paris). 1917;1:1-3.

2. Mohr JP. Distal field infarction. Neurology. 1969;19:279.

3. Sage JI, Van Uitert RL. Man-in-the-barrel syndrome. Neurology. 1986;36(8):1102-1103.

4. Alpert JN. Transient attacks of man-in-the-barrel syndrome. South Med J. 2010;103(1):72-73.

5. Antelo MJ, Facal TL, Sánchez TP, et al. Man-in-the-barrel. A case of cervical spinal cord infarction and review of the literature. Open Neurol J. 2013:7:7-10.

6. Berg D, Müllges W, Koltzenburg M, et al. Man-in-the-barrel syndrome caused by cervical spinal cord infarction. Acta Neurol Scand. 1998;97(6):417-419.

7. Flanagan EP, McKeon A, Weinshenker BG. Anterior spinal artery infarction causing man-in-the-barrel syndrome. Neurol Clin Pract. 2014:4(3):268-269.

8. Rouanet C, Reges D, Rocha E, et al. "Man in the barrel" syndrome with anterior spinal artery infarct due to vertebral artery dissection. J Stroke Cerebrovasc Dis. 2017;26(3):e41-e42.

9. Joaquim AF, Shaffrey CC, Sansur CA, et al. Man-in-the-barrel syndrome after thoracoilium fusion. J Neurosurg Spine. 2008;9(6): 566-569.

10. Orsini M, Catharino AM, Catharino FM, et al. Man-in-the-barrel syndrome, a symmetrical proximal brachial amyotrophic diplegia related to motor neuron diseases: a survey of nine cases. Rev Assoc Med Bras (1992). 2009;55(6):712-715.

11. Díaz-Nicolás S, López-Fernández JC, González-Hernández A, et al. Acute bilateral brachial plexopathy after abdominal surgery mimicking a man-in-the barrel syndrome. Article in Spanish. Rev Neurol. 2008;47(12):670-671.

12. Foncea N, Yurrebaso I, Gómez Beldarrain M, Garcia-Moncó JC. Postoperative bilateral brachial plexopathy mimicking the "man-inthe-barrel" syndrome. Article in Spanish. Neurologia. 2002; 17(7):388-390.

13. Asmaro K, Pabaney AH, Rammo R, et al. Man-in-the-barrel syndrome: case report of ventral epidural abscess and review of the literature. Surg Neurol Int. 2018;9:8.

14. Barbizet J, Degos JD, Hurth M, et al. Brachial diplegia due to ischemia of the anterior horns during septicemia caused by
Salmonella typhimurium. Article in French. Ann Med Interne (Paris). 1974;125(2):191-194.

15. Ben Sassi S, El Euch G, Regaieg A, et al. Man-in-the-barrel syndrome with combination of infarctions in the anterior spinal artery and posterior inferior cerebellar artery territories. Cerebrovasc Dis. 2009;27(2):201-202.

16. Butterfield MC, DeBlieux P, Palacios E. Man in a barrel: acute central cord syndrome after minor injury. J Emerg Med. 2015;48(3): 333-334.

17. Fuentes JM, Vlahovitch B, Nègre C. Brachial diplegia of traumatic origin as a result of injuries of the cervical cord. Article in French. Neurochirurgie. 1984;30(3):165-170.

18. Katz JS, Wolfe GI, Andersson PB, et al. Brachial amyotrophic diplegia: a slowly progressive motor neuron disorder. Neurology. 1999:53(5):1071-1076.

19. Lai NY, Purdie G. Acute cervical cord injury complicating KlippelFeil deformity and mimicking 'man in the barrel' syndrome. J Clin Neurosci. 1998;5(3):338-339.

20. Rajabally YA, Hbahbih M, Messios N, et al. Brachial diplegia as a result of cervical cord injury. Spinal Cord. 2005;43(6): 389-391.

21. Renard JF, Massardier E, lasci L, et al. Brachial diplegia caused by cervical spinal cord ischemia. A case. Article in French. Rev Neurol (Paris). 1997;153(11):690-693.

22. Rodríguez-Vico JS, Berrocal-Izquierdo N, Duarte J. Cervical spine myelopathy as a cause of man-in-the-barrel syndrome. Article in Spanish. Rev Neurol. 2010;51(11):701-703.

23. Soubrier M, Demarquilly F, Urosevic Z, et al. Cervical epidural infection. Four case-reports. Rev Rhum Engl Ed. 1995;62(1): 29-34.

24. Strupp M, Brückmann H, Hamann GF, et al. Simultaneous brachial diplegia and rotational vertigo due to combined spinal anterior and vertebrobasilar embolism. Eur Neurol. 2000; 43(4):240-242.

25. Vural G, Gumusyayla S, Bektas H, et al. Man-in-the-barrel syndrome: acute bilateral brachial plexopathy after recurrent microtrauma. J Pak Med Assoc. 2019;69(5):725-727.

26. Yoon BA, Kim JJ, Ha DH. A case of man-in-the-barrel syndrome induced by cervical spinal cord ischemia. Korean Soc Clin Neurophysiol. 2013;15:59-62.

27. Bell HS. Paralysis of both arms from injury of the upper portion of the pyramidal decussation: "cruciate paralysis." J Neurosurg. 1970; 33(4):376-380.

28. Hurley JP, Wood AE. Isolated man-in-the-barrel syndrome following cardiac surgery. Thorac Cardiovasc Surg. 1993;41(4): 252-254.

29. Olejniczak PG, Ellenberg MR, Eilender LM, et al. Man-in-thebarrel syndrome in a noncomatose patient: a case report. Arch Phys Med Rehabil. 1991;72(12):1021-1023.

30. Hashimoto M, Mochizuki M, Aiba A, et al. C5 palsy following anterior decompression and spinal fusion for cervical degenerative diseases. Eur Spine J. 2010;19(10):1702-1710.

31. Chiba K, Toyama Y, Matsumoto M, et al. Segmental motor paralysis after expansive open-door laminoplasty. Spine (Phila $\mathrm{Pa}$ 1976). 2002;27(19):2108-2115.

32. Hasegawa K, Homma T, Chiba Y. Upper extremity palsy following cervical decompression surgery results from a transient spinal cord lesion. Spine (Phila Pa 1976). 2007;32(6):E197-E202.

33. Hirabayashi K, Toyama Y, Chiba K. Expansive laminoplasty for myelopathy in ossification of the longitudinal ligament. Clin Orthop Relat Res. 1999;(359):35-48.

34. Tsuzuki N, Abe R, Saiki K, et al. Paralysis of the arm after posterior decompression of the cervical spinal cord. II. Analyses of clinical findings. Eur Spine J. 1993;2(4):197-202. 


\section{Disclosures}

The authors report no conflict of interest concerning the materials or methods used in this study or the findings specified in this paper.

\section{Author Contributions}

Conception and design: CB Shields, LBE Shields, VG lyer. Acquisition of data: CB Shields, LBE Shields, VG lyer. Analysis and interpretation of data: CB Shields, LBE Shields, VG lyer. Drafting the article: LBE Shields. Critically revising the article: CB Shields, LBE Shields, VG lyer, YP Zhang. Reviewed submitted version of manuscript: CB Shields, LBE Shields, VG lyer, YP Zhang. Approved the final version of the manuscript on behalf of all authors: $C B$ Shields. Administrative/ technical/material support: CB Shields. Study supervisions: CB Shields.

\section{Correspondence}

Christopher B. Shields: Norton Neuroscience Institute, Norton Healthcare, Louisville, KY. cbshields1@gmail.com. 